\title{
Desertification in the Upper West Region of Ghana: Causes, Processes and Impact
}

\author{
Emmanuel Amankwah \\ Department of Agricultural Engineering, Wa Polytechnic, \\ P.O. Box 553, Wa, Upper West Region, Ghana \\ Email:trustee7a@yahoo.com
}

\begin{abstract}
This paper is written to find out the causes, processes and impact of desertification in the Upper West Region and to suggest ways to address the problem. The research was conducted through interviews, field survey, using questionnaires and focus group discussions. It was realized during the research that the people in the region are aware of the environmental degradation but have varied views on the causes and their consequences. They realized the reduction in crop yield in recent years, the changing weather pattern, the drying up of streams and river bodies and many others, which are as a result of the human activities that negatively affect the environment. The research also discovered that felling down of trees for charcoal production, wood fuel and bush burning top the list of environmental degradation in the region. It was concluded by proposing measures such as afforestation, proper land management, introduction of fine or punishment for bush burning and enforcement of forest regulations in curbing the rate of environmental degradation that leads to desertification in the region.
\end{abstract}

Keywords: Desertification; Environmental degradation; Tree felling; Bush burning and charcoal.

\section{Introduction}

Destruction of forest resources leading to desertification has severe impact on wildlife habitat and biodiversity, with potentially irreversible losses to animal and plant life. According to Saigo (1992), desertification is the process of denuding and degrading a once-fertile land that initiates a desert -producing cycle that feeds on itself. Ghana's state of the environment document (EPA 2004) also explains desertification as caused by biophysical and socioeconomic factors such as overgrazing, over cultivation, deforestation, bushfires, excessive use of agrochemicals, mining and poor farming practices. Environmental degradation may have local, national and global consequences with significant impact on third world countries like Ghana. In December 1989, there was a call by the United Nations General Assembly to devise strategies in curbing and reversing the effects of environmental degradation to ensure sustainable and environmentally sound development. A resolution adopted by the General Assembly attest to the fact that there is a growing concern about the continuing spread and intensification of desertification in developing countries, particularly in
Africa, leading to human suffering, economic and financial losses, and social disruption (UNEP, 1989).

In Rio de Janeiro Conference on the environment in 1992, the preamble of Agenda 21 emphasized on the need for better management, protection of the ecosystem and taking preventive measures for lands that are not yet degraded. Desertification has been declared as the most serious environmental and socioeconomic challenge of the world culminating from complex interactions of physical, biological, chemical, socio-economic and political factors (UNEP, 1999).

Desertification affects the lives of over a billion people in the world and $70 \%$ of about 3.6 billion hectares of land; about $\$ 32$ billion, including $\$ 3.2$ billion in international grants or concessional funding was spent in combating deforestation between 1993 2000 in developing countries (UNEP, 1994). According to Cleaver and Schreiber (1994), the forest area in Africa is diminishing very fast at the rate of about 2.9 million ha/year due to the conversion of land for agriculture, infrastructure development in environmentally delicate areas, extraction, and commercial fuel wood harvesting. 
Wood fuel is the common energy source for majority of the rural poor and women and children usually spend long hours collecting wood fuel from distance sources and eventually use crop residues and manure which would otherwise have been used to maintain soil fertility due to scarcity of wood fuel (ibid). Many women also use the forest resources to meet subsistence needs or generate cash income for their survival (FAO, 1989). According to Enger and Smith (2008), wood fuel is the major source of fuel for less developed countries for centuries and energy for about half of the world's population mainly for cooking. Lanly (1982) cited by Cleaver and Schreiber (1994), also stated that about 3.7 million hectares of tropical Africa forests and open woodlands are cleared every year by farmers and loggers. It is also estimated that about $40 \%$ of the world's land cover has been converted to cropland and permanent pasture (Enger and Smith, 2008). The destruction of forest and woodlands result in high cost of timber for construction and wood fuel which is the staple source of household energy in Africa.

Removal of protective vegetation covers by tree felling or cultivation leads to an increase in surface run-off resulting in erosion with its damning consequences such as reduction of infiltration, loss of soil fertility (loss of soil nutrients), water pollution and flooding (Wild, 2001). A report by Kaule (2000) revealed that over 3 million $\mathrm{km} 2$ of global land has very high degree of desertification hazards, of which 1 million are in the arid zone, over 2 million in the semiarid and about 160,000 in the sub-humid zones.

In Africa, almost 17 million $\mathrm{km}^{2}$ of land is affected by desertification in various degree with an extreme desertification over 6 million $\mathrm{km}^{2}$. Apart from Africa, continents like Asia, North and Central America and Australia also suffer from the vagaries of desertification. A cross section of the land in the Upper West Region (UWR) of Ghana is gradually turning into grassland leading to complete desertification. The editorial section of the daily graphic on $21^{\text {st }}$ May, 2007 stated that about $35 \%$ of the total land area of Ghana is subjected to desertification. The northern part of Ghana is gradually having reduced vegetation cover and requires concerted effort to address the problem.

Places where charcoal burning has been practiced can no longer enjoy good vegetative cover. The soil, which provides home for soil fauna such as microbes, worms and insects, is destroyed by these activities. This biotic community which provide the means for plant growth as well as the foundation for life of human beings is destroyed by deforestation. It is therefore not out of place when the Savannah Accelerated Development Authority (SADA) was established to implement programmes aimed at environmental renewal to improve water resources management and disaster preparedness to reduce the impact of disaster and climate change in the Northern Savannah Ecological Zone (SADA, 2010). The need to review our policies, legislations and adopt new strategies to address the issues comprehensively cannot therefore be down-played.

\section{Methodology}

This research was carried out by undertaking an initial general survey on the state of the environment (the vegetative cover) of the eight (8) districts of the Upper West Region. There was an initial trip from Wa to Hamile through Jirapa, Lawra and Nandom. The next visit was from Wa to Gwollu through Funsi and Tumu. Another visit to Wa West (Wechiau) and other communities within the Wa Municipality. The duration of the exercise was about six to eight months and it was in conjunction with the Industrial Liaison Office of Wa Polytechnic. Existing information and knowledge on previous work done on desertification in Ghana especially in the Upper West Region through books, journals, articles, reports and the internet were reviewed.

Sixty-five questionnaires were administered to find people's perception on the state of the environment in the region, their understanding of desertification, causes, processes and impact, and adaptation strategy to use. Interviews were conducted and questionnaires administered among lecturers, students from University of Development Studies and Wa Polytechnic, workers and farmers within the region. Focus group discussion centred on lecturers and some of the final year students from the region. It was done to garner adequate information on the causes of environmental degradation in the region and the way forward to address the problem. All the information gathered were critically analysed using SPSS, EPINFO and basic excel tools.

\section{Results}

The outcomes of the research are presented in this section. The age group of respondents ranged from 15 to 55 years. Age group (25-40) tops the list with 54\% followed by $15-24$ with $37 \%$. Out of the number, $48 \%$ and $34 \%$ have had tertiary and secondary education 
respectively. The total number of respondents was sixty five (65). The responses made on the causes of desertification in the region are presented in Table 1.

Table 1

Respondents' response to desertification in the region

\begin{tabular}{lcc}
\hline $\begin{array}{l}\text { Traces of } \\
\text { desertification }\end{array}$ & Frequency & Percentages (\%) \\
\hline Yes & 62 & 95 \\
No & 3 & 5 \\
Total & 65 & 100 \\
\hline
\end{tabular}

Source: Field survey

From the context of desertification, $95 \%$ of the entire respondents affirmed some traces of desertification in the region. Only $5 \%$ of the people had different view claiming that it depends on how one looks at the situation. About $90 \%$ of the respondent attributed the causes of desertification to indiscriminate felling of trees for charcoal production as well as bush burning (see Figure 1). Charcoal was found to be the major form of energy for about $80 \%$ of the respondents. From Figure 1, charcoal production tops the causes of desertification (60\%) followed by woodfuel $(18.5 \%)$ and Bush burning (14\%) in the region.

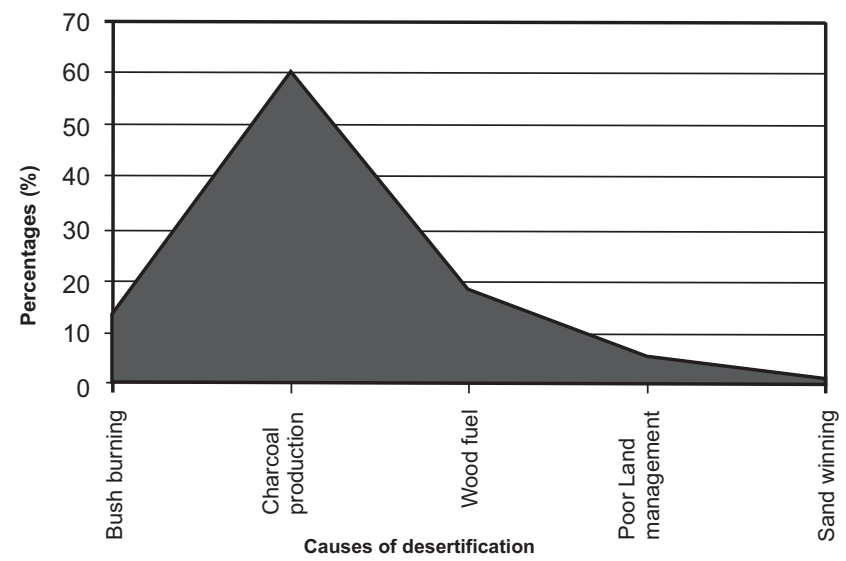

Fig. 1: Causes of desertification from respondents

The high rate of tree felling for charcoal production is as a result of the lack of economic activities in the region during the dry season. Farmers in the region therefore depend on charcoal production especially during the dry season for their survival. Charcoal has been the main source of energy for urban dwellers especially when there is no Liquefied Petroleum Gas (LPG) which is the main source of energy.

On the effect of desertification on the climate, the respondents showed that they had seen changes in the weather pattern within the region over the last decades. Figure 2 show responses made on changes observed in the weather pattern. From the figure, it will be seen that thirty seven percent $(37 \%)$ said there has been changes in the rainfall pattern, $35 \%$ indicated a change in temperature/sunshine while $9 \%$ also realized a change in storms. However $19 \%$ indicated a change in all the climatic factors listed in Figure 2. Trees are to serve as carbon sink to avert climate change thus clearing them for charcoal production will have damning consequences.

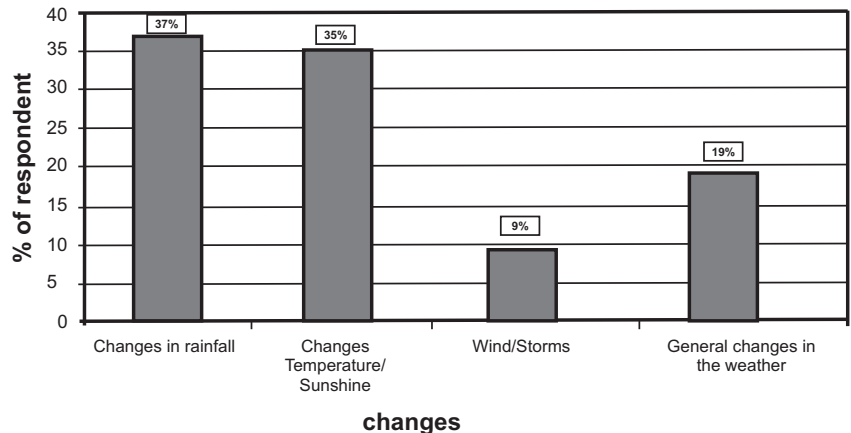

Source: Field survey

Fig. 2: Changes in weather pattern

Questions on the impact or effect of desertification were asked and the respondents listed the following implications: poverty, soil infertility, hunger, malnutrition and high infant mortality rate. The entire respondent acknowledged that desertification is something that can hamper growth and development, and cause reduction in food production. Ninety-five percent of the respondent accepted that they have a role to play in curbing such a menace but $5 \%$ argued that it is the responsibility of Environmental Protection Agency (EPA), District Assemblies and other organizations to deal with the issue of desertification in the region. Figure 3 indicates measures respondents outlined for solving the problem of desertification in the region.

Out of the 65 respondents, $39 \%$ proposed public education, $20 \%$ proposed stern sanctions and punishment, $17 \%$ for laws on bush fires and tree felling while $15 \%$ thinks the formation of anti bushfire committees could solve the problem and only $9 \%$ suggested the eradication of culturalpractices and beliefs.

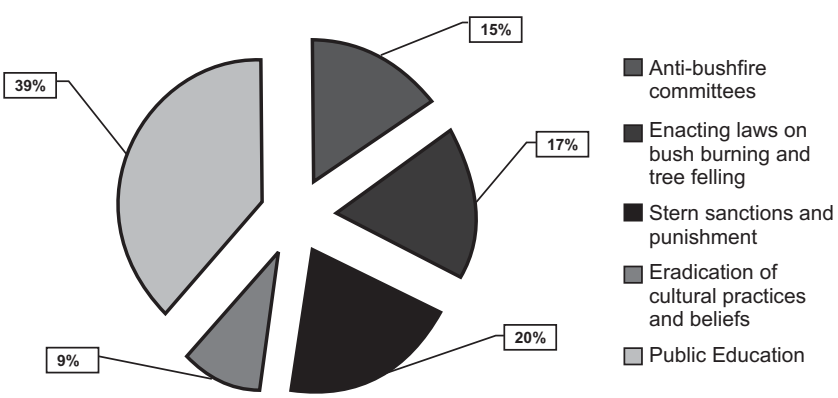

Fig.3: Proposed solution to desertification 


\section{Discussion of results}

The research revealed that some people in the UWR believe that there is a clear evidence of desertification traces in the region. Even though desertification could occur as a result of natural factors, the issues in the UWR are mainly human induced factors. The anthropogenic factors such as indiscriminate felling of trees for charcoal production, fuel wood and bush burning are the cause of environmental degradation and such practices will have damning consequences on the region and this assertion is supported by (Wild 2001). Besides, overgrazing, poor farming practices, resettlement, poor irrigation practices, poor application of agrochemicals, sand winning and construction have also contributed to the poor environmental conditions in the region. These factors have also resulted in an unpredicted weather change, human suffering, economic and financial losses in the region as indicated in UNEP 1989.

Due to environmental degradation, rainfall pattern has changed and it is difficult to predict the rains, the region is experiencing high temperatures and droughts. Certain animals and plants species are closed to extinction which agrees with Saigo 1992 that plants and animals lives are lost due to desertification. The removal of trees and vegetative cover will lead to change in climate which effect is likely to affect the achievement of the Millennium Development Goals (MDGs) on sustainable development by 2015. Eager and Smith (1994) claim that wood fuel is the major source of fuel for less developed countries still holds as the research revealed that charcoal and wood fuel which is mainly used for cooking have been the major cause of desertification.

It is noteworthy that some of the respondents, mainly the youth, with higher education are aware of the degradation and have proposed measures to address the problem. It is therefore imperative that the youth are engaged to address the problem through vigorous education, reafforestation programmes and enactment of the laws to bring about the needed change. Even though combating desertification is very expensive (UNEP, 1994) but the long term solution to the problem will save the economy and reduce the threat of climate change. Impact of desertification is very disastrous and requires the attention of all stakeholders as the region is gradually turning into grassland. Fortunately, SADA has been constituted to response to the effect of climate change associated with floods and drought in the region and to promote sustainable development through afforestation and green north.

Unfortunately, some of the reasons given for bush burning; to drive away snakes, to clear the land from weeds, for bush meat and many more cannot be substantiated. Despite the loss of vegetative cover, bush burning affects the microorganisms in the soil, destroy soil texture, deplete soil nutrients and accelerate soil erosion. These factors will worsen the plight of the people in the region especially farmers.

The research revealed that the most important tool for change of attitude towards the environment is education. It is therefore imperative that chieftaincy institutions, National Commission for Civic Education, Information Departments, community groups and other educational institutions should embark on vigorous educational campaign against environmental degradation and forest preservation. It was also observed during the research that charcoal production declines during the farming season and rises during the lean season. Farmers are not able to cultivate throughout the year thus engage in charcoal production for survival. It is therefore paramount that irrigation facilities are provided to warrant all year farming to save farmers from engaging in charcoal production. This will drastically reduce the rate of deforestation in the region.

Ghana being a signatory to the United Nation Convention for Combating Desertification (UNCCD) should take keen interest in combating desertification with the support of the international community. The proposed solution when put into practice will address the issue of desertification with its concomitant threats.

\subsection{Effect of desertification on socio-economy and the environment}

The environment is us and we derive air, food and water from it thus the negative effect of desertification will affect the socio-economic wellbeing of the people. The World Bank revealed during a durbar organized to mark the 2011 World Desertification Day at Wechiau that Ghana loses between 2-5\% of agricultural GDP. It was therefore not out of place when the World Bank and CIDA jointly voted one million US dollars to combat desertification and drought in Ghana. Desertification will lead to drought, soil infertility and loss of vegetative cover which eventually results in low food production and food insecurity.

Even though charcoal production seems to provide some support for farmers during the dry 
season in the short term but the long term consequences could be disastrous and leads to poverty and compromise on basic life sustaining factors. Land degradation has lead to the decline of the standard of living of rural people who depend on the forest for their survival. Government through the National Disaster Management (NADMO) has to spend a lot of money and materials to alleviate the plight of communities affected by the effect of desertification. The impact is summarized in Figure 4.
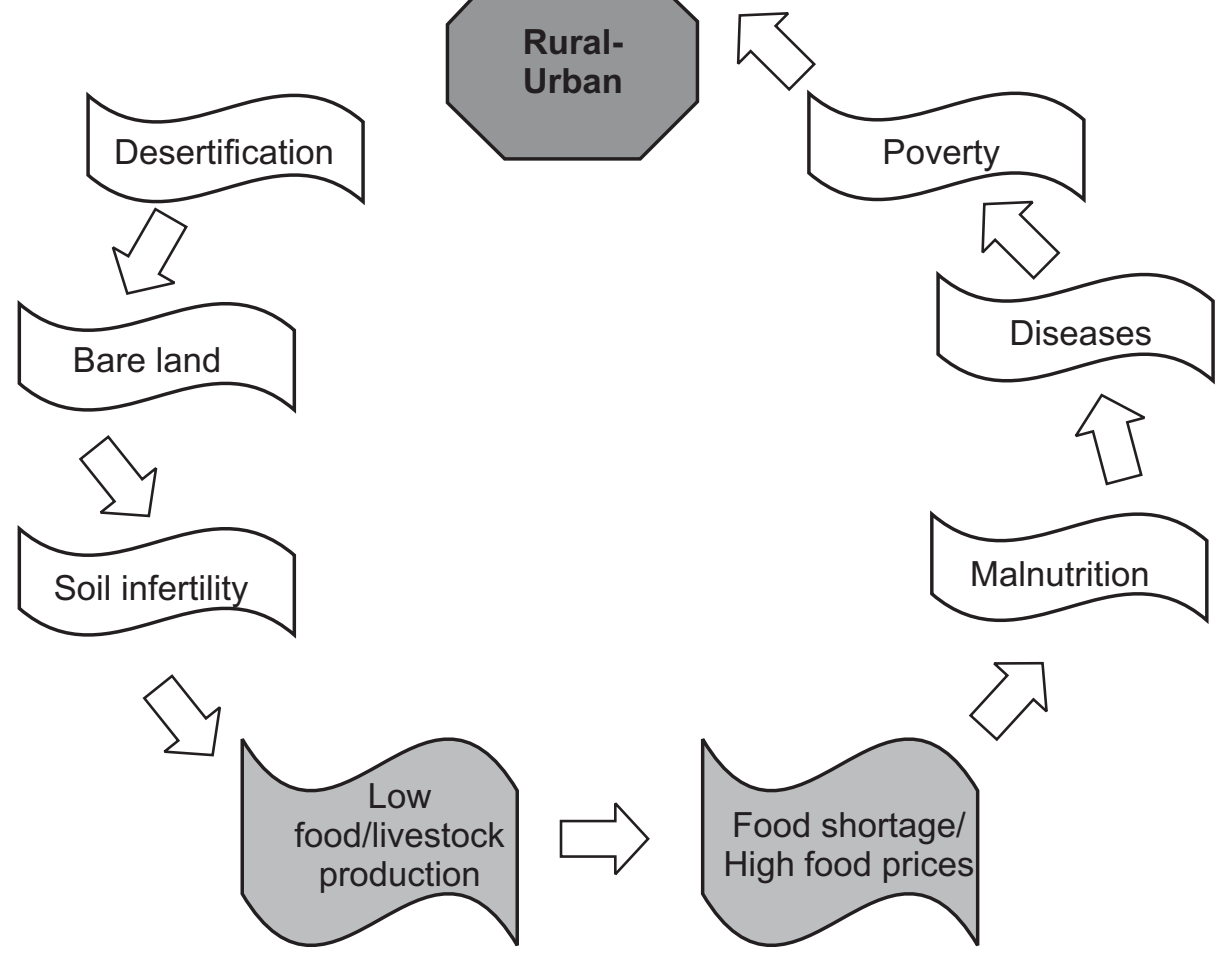

Fig. 4: Summary of the socio-economic impact of desertification

\section{Conclusion and recommendations}

It was observed that the causes of desertification are mainly human induced factors and could therefore be addressed. It requires concerted effort to fight desertification. Poverty, ignorance, negligence and illiteracy should not be an excuse for environmental degradation. However, whatever measures adopted should be accompanied with poverty alleviation packages which will serve as incentives for the people to desist from the negative practices that degrade the environment. In solving the problem, members of the community should not be ignored but be fully involved in the action plan since they are aware of the situation. Also the indigenous institutions such as the chieftancy and cultural organizations, governmental and non-governmental organizations, women groups and opinion leaders should also be involved. The following are therefore recommended for consideration:

- Intensify public educational campaign on desertification and its consequences through the electronic and print media.
- Encourage farmers, students, the youth to form groups and clubs to embark on reafforestation programmes using fireresistance and fast growing plant species in their communities

- Form anti-bush fire committees, enact and enforce by-laws for environmental conservation

- Strengthen the institutional and logistical capacity of environmental related institutions such as Environmental Protection Agency and Ministry of Science and Environment to widens their environmental monitoring network in the country

- Provide incentives and financial support to groups and organizations working towards environmental conservation and combating desertification

- Educate farmers to adopt environmentally sound agriculture through sustainable use and management of land and water resources. 


\section{References}

Cleaver, M. K. ,and Schreiber, A. G., (1994). Reversing the Spiral. The Population, Agriculture and Environment Nexus in Sub-Sabaran Africa. The World Bank, Washington. D.C.

Enger, D.E., and. Smith, F.B., (2008). Environmental Science: A Study of Interrelationships. (11 ${ }^{\text {th }}$ Edition.). McGraw Hill, USA.

EPA., (2004). Ghana's State of the Environment. Ghana.

FAO., (1989). Environment and Agriculture: Environmental Problems Affecting Agriculture in the Asia and Pacific Region. World Food Day Symposium, Bangkok.

GHS., (2008). Annual Report on health services in the Upper West Region. Ghana Health Service, Wa.

Kaule, G., (2000). Ecologically Orientated Planning. Peter Lang.

Lanly, J.P., (1982). Tropical Forest Resources. FAO Forestry Paper No. 30. Food and Agriculture Organization of the United Nations, Rome.
Nsiah-Gyabaah, K., (1994). Environmental Degradation and Desertification in Ghana: A Study of the Upper West Region. Ashgate Publishing Limited.

Saigo, W.B., and Cunningham ,P. W., (1992). Environmental Science: A global Concern.

UNEP., (1989). Plan of Action to Combat Desertification. Sudano-Sahelian

UNEP., (1994). Population and Environment, Vol. 6, No. 3

UNEP., (1999). Global Environmental Outlook 2000. Earthscan Publication Ltd, Wm. C. Brown Publishers, USA.

Wild, A., (2001). Soils and the Environment, An introduction. Cambridge University Press.

http://www.ghanabusinessnews.com., : Desertificationdevastates-african-economiesghana-loses-5-ofagricultural-gdp/ (retrieved on 22/10/11) 